\title{
RESEARCH
}

Open Access

\section{Oral health related quality of life of children and adolescents affected by rare orofacial diseases: a questionnaire-based cohort study}

Lisa Friedlander ${ }^{1,2,3^{*}}$ (D) Ariane Berdal ${ }^{2,3,4}$, Priscilla Boizeau ${ }^{5,6}$, Brigitte Alliot Licht $^{3,7}$, Marie-Cécile Manière ${ }^{3,8}$, Arnaud Picard ${ }^{3,9,10}$, Olivier Azzis ${ }^{3,11}$, Marie-Paule Vazquez ${ }^{3,9,10}$, Corinne Alberti ${ }^{1,5,6}$ and Muriel De La Dure Molla ${ }^{2,3,12}$

\begin{abstract}
Background: Rare diseases affecting the teeth, the oral cavity and the face are numerous, each of them present specific characteristics, and is a life-long condition. The aim of the study was to assess the association between Oral health-related quality of life (OHRQoL), and demographic characteristics, clinical and dental factors, and psycho-social characteristics to investigate that oral symptoms are not the main factors underlying a decrease in OHRQoL.

Material and methods: We conducted a national cohort study in French centres for rare diseases (RD) specialized in orofacial diseases. The inclusion criteria were: to have received care in RD centres over the last 5 years (2012-2017) and to have been between 6 and 17 years of age on September 1, 2017. Patients were invited to answer a questionnaire composed of socio-demographic, clinical and dental questions, psychosocial questions and then fill in the Child-OIDP Index. At the end of the questionnaire, a free space was left for the patient to add a verbatim comment to provide qualitative data. Thematic analysis was used to analyze the verbatim answers.

Results: Complete data were available for 110 patients. The sample included $44.5 \%$ boys and $55.5 \%$ girls. Ages ranged from 6 to 17 years old and $68.2 \%$ were between 6 to 12 years old and $31.8 \%$ were between 13 and 17 years old. Factor associated with a lower OHRQoL were: being a girl $(p=0.03)$, renouncement to dental care for financial reasons $(p=0.01)$, having syndromic disease $(p=0.01)$, having a problem with tooth shape and color $(p=0.03)$, feeling isolated, alone and different from other children ( $p=0.003$ and $p=0.02$ ). Qualitative analysis highlighted very little recourse to psychological care and patients reported great anxiety and fear about the future.

Conclusion: OHRQoL of children suffering from these diseases is impaired, especially from the psychosocial point of view but also from that of the course of treatment and access to care. There is a need to improve the legibility of care pathways and the financial coverage of treatments.
\end{abstract}

Keywords: Rare disease, Cleft, Oral manifestation, Teeth, Oral health-related quality of life (OHRQoL), Child, CHILD-OIDP

\footnotetext{
* Correspondence: lisa.friedlander@inserm.fr

'Sorbonne Paris Cité, INSERM, Laboratoire ECEVE UMR1123, Université Paris

Diderot, Paris, France

${ }^{2}$ Centre de Reference, Maladies Orales et Dentaires Rares, Hopital Rothschild,

APHP, Paris, France

Full list of author information is available at the end of the article
}

(c) The Author(s). 2019 Open Access This article is distributed under the terms of the Creative Commons Attribution 4.0 International License (http://creativecommons.org/licenses/by/4.0/), which permits unrestricted use, distribution, and reproduction in any medium, provided you give appropriate credit to the original author(s) and the source, provide a link to the Creative Commons license, and indicate if changes were made. The Creative Commons Public Domain Dedication waiver (http://creativecommons.org/publicdomain/zero/1.0/) applies to the data made available in this article, unless otherwise stated. 


\section{Background}

Rare dieases affecting the teeth, the oral cavity and the face are numerous although each specific disease is rare. Oral clefts and diseases such as multiple dental agenesis and amelogenesis imperfecta are examples of genetic conditions that affect head, neck and teeth in isolation or as part of a syndrome. These pathologies affecting the face have consequences on both appearance and oral function. Therapy involves a multidisciplinary team encompassing surgery, dental care, and speech therapy $[1,2]$. Psychological management is needed because oral and general OHRQol are always impacted [2-4]. Indeed, with regard to facial clefts, surgical management begins in the first months of life and carries on throughout childhood, then from adolescence with orthodontic care and often in adult life with implants and prosthetic care [5].

More specifically, alteration of self-image was reported due to the facial malformation and handicap often generated [6,7]. Educational integration, in terms of both social relations and school level, may be impaired by the disease [8].

To these difficulties are added financial issues. Dental prosthetic rehabilitation is poorly reimbursed in many countries such as France. In addition, travel costs are not supported and if the center of expertise is far from home, and costs can be important for families. Patients give up care for financial reasons [9].

Oral health-related quality of life has been extensively studied in the literature. It is now recognized that oral health cannot be dissociated from general health and therefore that oral health is a major component of the overall OHRQol but that oral parameters are not the only ones responsible for a lower general quality of life. According to the WHO, oral health affects people physically and psychologically, and not only influences how they grow, enjoy life, look, speak, chew, taste food and socialize, but also has an impact on their feelings of social well-being [10]. Our hypothesis was that elements like social and financial characteristics have a more negative effect on the oral health-related quality of life of young patients than the nature of the disease and its therapy. To validate this, we performed a quantitative and qualitative study to assess the association between OHRQol, and other factors such as demographic and psycho-social characteristics, clinical and dental factors, care course and renouncement of dental care. There are many scientifically validated tools available to study the oral health-related quality of life in children. In order to assess how these diseases affected patients' ability to fully accomplish everyday tasks, the CHILD-OIDP questionnaire validated in French by Tubert-Jeannin S. and al. in 2005 [11] and initially validated by Gherunpong, S. and all [12] was chosen.
In addition, we performed a qualitative analysis based on a free-answer question asked at the end of the questionnaire, so that the patients could freely express feelings about their diseases and life.

Our objective was to provide the public authorities with reliable elements for implementing public health policies that are as close as possible to the real needs of children suffering from these diseases.

\section{Material and methods Study design}

We conducted a national cohort study based on the RD network concerning the head, the neck and the teeth (TETECOU network).

Patients included in this network presented orofacial diseases. This network groups the 5 consultation centres included in this study.

\section{Recruitment}

In this study were included patients followed in centers of expertise for oral dental and facial rare diseases. Patients can be separated in two groups: oral diseases (syndromic or not) without facial cleft (for example: amelogenesis imperfecta, dentinogenesis imperfecta, enamel-renal syndrome, ectodermal dysplasia, oligodontia ...) and rare orofacial diseases with presence of a facial cleft (eg Cleft lip and cleft palate, Pierre Robin syndrome, Goldenhar syndrome). Isolated and syndromic diseases were included in the study.

The director of the centres sent a list of patients treated in the centres over the last 5 years (2012-2017).

Inclusion criteria were: patients between 6 and 17 years old on September 1, 2017, who had been diagnosed with a cleft and/or a RD with or-dental manifestations at one of the expertise centres of the TETECOU network and consenting to participate in the study.

Exclusion criteria were patients who did not speak French, patients under legal protection and patients residing outside France (lack of comparability of health systems).

\section{Oral health-related quality of life}

When applying the Child-OIDP, the children or their parents were asked to record a self-administrated version of the questionnaire. Patients recorded their oral problems (a list of dental problems was given in the questionnaire) during the last 3 months before they completed the questionnaire. The capacities of accomplishing certain functions were recorded (eating, speaking, cleaning mouth, sleeping, emotional status, smiling and social contact).

These 8 functions were rated on a 3-point scale, with possible answers ranging from "slight difficulty" to "medium difficulty", to "great difficulty" corresponding to the values from 1 to 3 assigned to each answer. 
For each task affected, the frequency was asked with possible answers ranging from "less than once a month" to " 1 to 3 times a month", to " 3 or 4 times a month", to "nearly every day"; response values ranging from 1 to 5 were assigned to each answer.

Each question was weighted in the same way; the maximum possible score was 100 points (worst possible result) and the lowest possible score was 0 point (best possible result). The mean values were calculated for each topic of the questionnaire as well as for the total score.

Higher scores thus indicated a lower OHRQol. The calculation of the score involved the multiplication of the severity and frequency for each function.

Patients were asked to complete a composite questionnaire composed of several parts: a socio-demographic part, a dental and clinical part, a psycho-social part then finally the CHILD-OIDP Index. Sociodemographic, clinical/dental, and psychosocial factors are described below.

\section{Potentially associated factors \\ Sociodemographic characteristics}

Patient age and gender were considered. The method of social coverage was considered, depending on whether the patient had: no social security cover, social security alone, social security and additional coverage, "CMUc" ("CMUc" is a free complementary health cover designed to facilitate access to healthcare for people with low income living in France), "100\% ALD" for their pathology (" $100 \%$ ALD" is awarded if certain long-term conditions are considered "exonerating" for some dental care, except prosthetic care). As for school, the factors observed were type of schooling (traditional, or with personalized support), whether there was a learning delay, the level of education (kindergarten, primary, secondary or university). Regarding the financial aspect of care, the factors observed were: whether or not to give up dental care for the child, whether they had received help for care (from the city, local authorities or social security).

\section{Clinical and dental characteristics}

Regarding patient phenotype, we recorded the nature of the anomaly (concerning face, teeth or both), the diagnosis of syndrome association. All the children in the study suffered from dental problems due to their pathology. Some however had an oral cleft in addition. For this reason, we separated the patients in two groups: with or without the presence of a cleft. The following oral symptoms were checked: (in terms of absence or presence) toothache, tooth sensitivity, presence of caries, spaces between teeth due to no eruption of permanent teeth, falling decidual teeth, staining of teeth, altered tooth size and shape, badly positioned teeth, bleeding gums, swollen gums, mouth ulcers (aphtha type), bad breath, deformity of the mouth (cleft lip or palate), a problem of eruption of permanent teeth, a problem of absence of definitive teeth. Dental treatment was also recorded, especially prosthetic rehabilitation (such as removable or fixed prosthesis), and orthodontic appliances.

\section{Psychosocial features}

Psychosocial and psychic distresses were evaluated recording two items: feeling different from other children and feeling isolated at school.

Patient's satisfaction about Communication between private doctors and doctors in hospital was assessed by asking the patients how they felt about this point.

\section{Data collection}

Eligible persons were informed about the objectives and the modalities of the study. The questionnaire was filled electronically or on paper.

They were contacted by post. They received a letter containing the following elements:

- A letter describing the objectives and modalities of the study and inviting them to participate,

- A form to be returned if the participant wished to receive a questionnaire in paper form or online form.

- A pre-stamped envelope.

Patients had two ways to fill out the questionnaire: 1 - by electronic means, with secure access to a dedicated site (secured by a personalized login and password). 2- by post: the respondents returned the form in the postage paid envelope and received the questionnaire in paper form and a pre-paid envelope.

In the event of non-response, a reminder letter (up letter) was sent one month after the first letter.

Data were recorded by one person (LF). The data management was performed to edit the data and verify the missing data.

\section{Statistical analysis}

The primary outcome was the CHILD-OIDP score.

The statistical analyses were performed on participants for whom the CHILD-OIDP and the potentially associated factors were recorded exhaustively.

Data were expressed in medians (1st; 3rd quartile), minimum and maximum for non-Gaussian continuous variables and in numbers (percentages) for categorical variables.

Bivariate and multivariate analyses were carried out to identify factors associated with the CHILD-OIDP using quantile regression. Beta coefficient and 95\% confidence intervals were calculated.

All the data were analyzed using SAS software (version 9.4; SAS Institute, Cary, NC, USA). 
All the statistical tests were bilateral with a significance level of $5 \%$, which means that a $p$-value $<5 \%$ was considered significant.

\section{Bivariate analyses}

As a preliminary step in the multivariate analyze, we performed bivariate analyses to examine the differences of the mean CHILD-OIDP score across subgroups of potentially associated factors.

\section{Multivariate analyses}

Significant factors at the $20 \%$ bivariate threshold were selected for the multivariate model. An automatic stepwise selection technique called "stepwise" was used. It allowed obtaining a model with only significant factors at $5 \%$, adjusted for age in 2 classes, gender and whether the disease was syndromic or not.

We tested the adequacy of the regression by graphically verifying that the assumptions of homoscedasticity and normality of the estimation errors were satisfied by building a scatter plot of the estimation errors against the estimated CHILD-OIDP scores and a quantile-quantile plot. As the distributions were not normally distributed, the quantitative data were summarized by the median (1st, 3rd quartile) and the minimum and maximum were also given.

\section{Qualitative methodology}

At the end of the questionnaire, a free space was left for the patient to add a verbatim if they wished. No specific question was asked; the order was simply to express freely what they wanted to say about the disease, the care course, their life or their children's life.

An inductive approach using thematic analysis was used to manually analyze the verbatim answers [13-15]. This method allowed organizing thematic and to identify and organize patterns. The objective was to precisely analyze the whole dataset. Topics were chosen for their prevalence and their importance in relation with the research question.

\section{Results}

Five expertise centres participated in the study. Two specialized in maxillo-facial surgery and three in oral surgery.

A list of 1168 patients was obtained from the centres. A sample was obtained after eliminating patients not living at the declared address, and by stratifying patients as a function of age, gender and disease type (cleft versus dental rare RD). The final analysis was performed on 440 children between 6 and 17 years old (Fig. 1). Overall, 108 patients did not receive the questionnaire because their address had changed, leading to the inclusion of 132 patients in the survey. Complete data (people whose score was calculable and who respected inclusion criteria) were available for 110 patients.

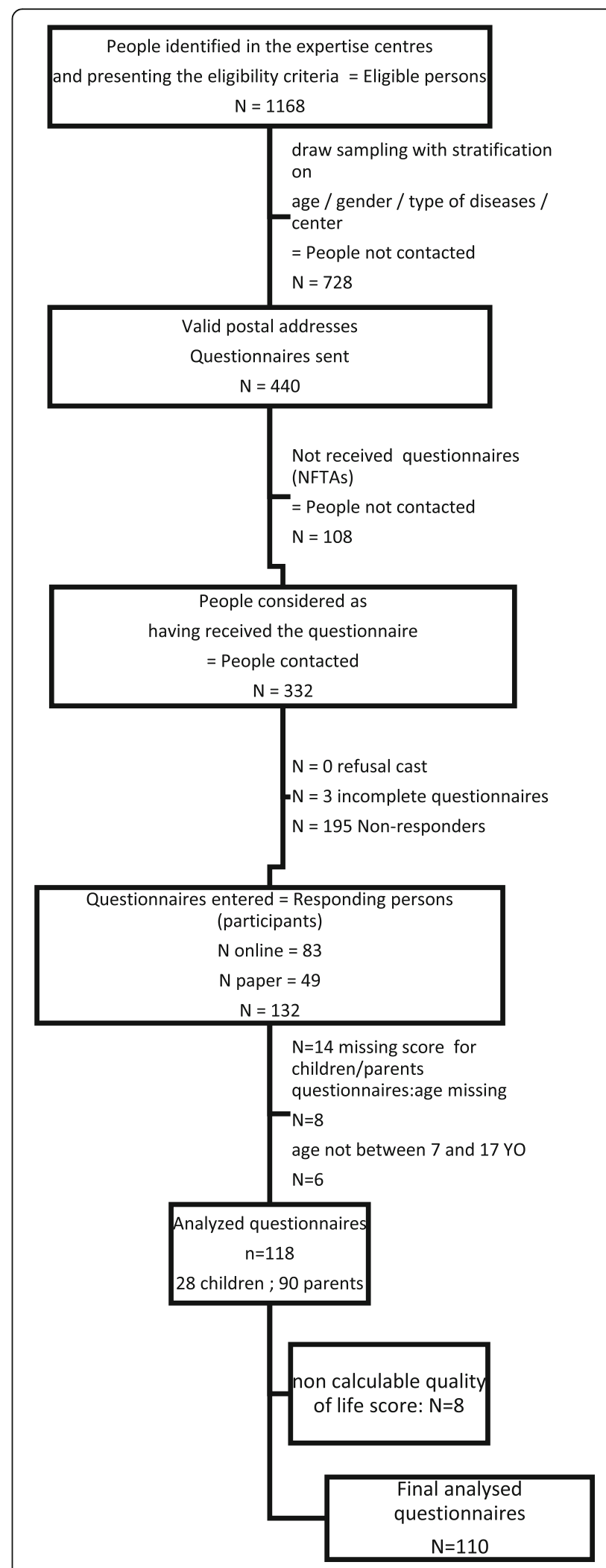

Fig. 1 Study flow chart 
The sample included 49 boys (44.5\%) and 61 girls (55.5\%). Ages ranged from 6 to 17 years old and 75 were between 6 to 12 years old (68.2\%) and 35 were between 13 and 17 years old (31.8\%).

Regarding the children's social coverage, 103 (94.5\%) of them were covered by social security and private health insurance. In this sample, 54 (55.1\%) of the children benefited from $100 \%$ coverage by social security ("100\% ALD").

Regarding the distribution by type of disease, 51 (51.5\%) of the children in this sample presented an oral cleft and $48(48.5 \%)$ of them had an isolated dental disease. There were $32(32.3 \%)$ of children affected by syndromic disease.

The OHRQol score, CHILD-OIDP, ranged from 6.7 to 80 with a median of 20.8 (Table 1 ).

\section{Bivariate analysis}

Sociodemographic variables, clinical, medical and psychosocial variables were compared to the OHRQol scoring. Regarding sociodemographic variables, being a girl was significantly associated with a lower OHRQol ( $\mathrm{p}=$ $0.03)$. Foregoing dental care for financial reasons was also associated with a lower OHRQol $(\mathrm{p}=0.01)($ Table 2$)$

For the clinical and medical variables, syndromic disease was significantly associated with a worse OHRQol

\begin{tabular}{ll} 
Table 1 Demographic and social description of the sample \\
\hline Variables & Description \\
\hline Gender & $N=110$ \\
Male & $49(45 \%)$ \\
Female & $61(55 \%)$ \\
Age subgroups & $\mathrm{N}=110$ \\
6-12 YO & $75(68.2 \%)$ \\
13-17 YO & $35(31.8 \%)$ \\
Social coverage & $\mathrm{N}=109$ \\
National coverage without private insurance & $2(1.8 \%)$ \\
"CMUc" & $4(3.7 \%)$ \\
National coverage with private insurance & $103(94.5 \%)$ \\
" 100\% ALD» & $\mathrm{N}=98$ \\
No & $44(44.9 \%)$ \\
Yes & $54(55.1 \%)$ \\
type of disease & $\mathrm{N}=99$ \\
Oral Cleft & $51(51.5 \%)$ \\
Dental diseases & $48(48.5 \%)$ \\
Syndromic disease & $\mathrm{N}=99$ \\
Syndromic & $32(32.3 \%)$ \\
Non-syndromic & $67(67.7 \%)$ \\
Index Child OIDP & $\mathrm{N}=110$ \\
Min; Max & $20.8(10.0 ; 35.0)$ \\
\hline & $6.7 ; 80.0$ \\
\hline
\end{tabular}

$(p=0.01)$. Having a problem of tooth shape and color was the only dental factor, among all the oral variables studied, associated with poorer OHRQol $(p=0.03)$ (Table 3).

Regarding psychosocial variables, feeling isolated and alone because of the disease was significantly associated with a lower OHRQol $(p=0.003)$. Feeling different from other children was also significantly associated with a lower OHRQol $(p=0.02)$.

On the other hand, the quality of relations between hospital and private medicine did not seem to have a significant influence on the OHRQol of patients. (Table 4).

\section{Multivariate analysis.}

A threshold of $20 \%$ in the bivariate model was chosen for the variables selected for the multivariate model (gender, academic delay, renouncement to dental care, syndromic disease, type of disease, orthodontic treatment, deciduous teeth, being sidelined in life, feeling different).

Multivariate analysis showed that the variables associated with a poorer OHRQol, adjusted on age in 2 classes: 6-12 years old / 13-17 years old, gender: male / female, syndromic disease or not, were: diagnosis of syndromic disease $(p=0.04)$, dental disease without the presence of a facial cleft $(p=0.002)$, problems with the shape and size of the teeth $(p=0.005)$ and feeling sidelined and alone $(p=0.003)$ (Table 5).

\section{Qualitative analysis}

The verbatim responses were analyzed for qualitative appreciation of patient illness. 36\% (40/110) of the patient answered. Thematic analysis was used to analyze the interview data [16]. All the verbatim responses can be found in the Additional file 1.

The topics addressed in these verbatim responses can be classified according to the following topics (Fig. 2): patients reported a lack of information on treatment and the course of care, and a lack of listening from medical and non-medical staff. Insufficient psychological care of children and their parents was reported. They also reported complicated relations between care in public hospital and care in private establishments (Topic 1).

Patients and their parents reported feelings of anxiety, loneliness and difficulties in facing the gaze of others. They expressed that spoiled smiles damage selfconfidence (Topic 2).

Patients and families complained about transport, stating that the best practitioners were far from home. Parents were forced to take a day off for the medical appointments of their children (Topic 3 ).

Patients reported many difficulties in the care course (Topic 4).

School and academic integration appeared to be bad. They reported learning delays, difficulties in becoming integrated in normal schools, and isolation from others (Topics 5). They also reported that pediatric metal caps 
Table 2 CHILD-OIDP score by socio-demographic characteristics $(N=110)$

\begin{tabular}{|c|c|c|c|c|c|c|}
\hline \multirow[t]{2}{*}{ Socio-demographic characteristics } & \multirow[t]{2}{*}{$\mathrm{n}$} & \multirow[t]{2}{*}{$\%$} & \multicolumn{2}{|l|}{ CHILD-OIDP score } & \multirow[t]{2}{*}{ Beta $[95 \% \mathrm{Cl}]$} & \multirow[t]{2}{*}{$P$ value } \\
\hline & & & Median (Q1; Q3) & Min; $\max$ & & \\
\hline \multicolumn{7}{|l|}{ Gender } \\
\hline Male & 49 & 44.5 & $15.0(7.5 ; 29.2)$ & $6.7 ; 66.7$ & 0.0 & - \\
\hline Female & 61 & 55.5 & $24.2(11.7 ; 40.0)$ & $6.7 ; 80.0$ & $9.2[0.7 ; 17.7]$ & 0.03 \\
\hline \multicolumn{7}{|l|}{ Age } \\
\hline $6-12$ years old & 75 & 68.2 & $20.8(10.0 ; 35.0)$ & $6.7 ; 80.0$ & 0.0 & - \\
\hline 13-17 years old & 35 & 31.8 & $22.5(9.2 ; 43.3)$ & $6.7 ; 61.7$ & $1.7[-9.2 ; 12.6]$ & 0.76 \\
\hline \multicolumn{7}{|l|}{ Education level } \\
\hline Pre-school/Primary School & 72 & 65.5 & $20.8(10.8 ; 35.0)$ & $6.7 ; 80.0$ & 0.0 & - \\
\hline College/University & 38 & 34.5 & $21.3(8.3 ; 40.0)$ & $6.7 ; 72.5$ & $1.7[-8.3 ; 11.7]$ & 0.74 \\
\hline \multicolumn{7}{|l|}{ Type of school } \\
\hline Traditional & 89 & 82.4 & $17.5(9.2 ; 30.8)$ & $6.7 ; 66.7$ & 0.0 & . \\
\hline Personalized & 19 & 17.6 & $29.2(16.7 ; 61.7)$ & $6.7 ; 80.0$ & $11.7[-9.6 ; 33.0]$ & 0.28 \\
\hline \multicolumn{7}{|l|}{ Academic delay } \\
\hline No & 94 & 85.5 & $17.9(9.2 ; 33.3)$ & $6.7 ; 80.0$ & 0.0 & . \\
\hline Yes & 16 & 14.5 & $33.0(21.3 ; 52.1)$ & $9.2 ; 77.5$ & $13.4[-2.0 ; 28.8]$ & 0.09 \\
\hline \multicolumn{7}{|l|}{$100 \%$ ALD } \\
\hline No & 44 & 44.9 & $19.6(9.2 ; 33.8)$ & $6.7 ; 66.7$ & 0.0 & \\
\hline Yes & 54 & 55.1 & $25.0(11.7 ; 40.0)$ & $6.7 ; 80.0$ & $5.0[-4.5 ; 14.5]$ & 0.30 \\
\hline \multicolumn{7}{|l|}{ Renouncement to dental care } \\
\hline No & 97 & 89.0 & $20.0(9.2 ; 33.3)$ & $6.7 ; 80.0$ & 0.0 & . \\
\hline Yes & 12 & 11.0 & $40.9(17.9 ; 44.6)$ & $6.7 ; 62.5$ & $20.0[4.1 ; 35.9]$ & 0.01 \\
\hline \multicolumn{7}{|l|}{ Financial help received for dental care } \\
\hline No & 96 & 91.4 & $20.0(9.2 ; 34.6)$ & $6.7 ; 80.0$ & 0.0 & . \\
\hline Yes & 9 & 8.6 & 31.7 (25.0; 50.8) & $10.0 ; 77.5$ & $11.7[-9.3 ; 32.7]$ & 0.27 \\
\hline
\end{tabular}

Bold indicates $p$ values under 0.05 .

were very visible in the mouth and had many impacts on smiling. Patients reported several daily life-dental issues: pain, difficulty when eating, brushing teeth, altered tooth color, reduced chewing surface, lack of saliva, restricted mouth opening (Topics 6).

A large proportion of patients reported budget and financial issues. Patients reported their deception according to social coverage: problem of excess fees (treatments too expensive and not enough reimbursed), feeling that the lack of financial assistance was not acceptable (Topic 7).

The patients and most parents reported anxiety and fear about the future. They had doubts about the most competent practitioner to treat their children. Children reported anxiety related to the fear of pain. Parents reported their impression of "fighting alone", and their fear of the impact of teeth on overall health (Topic 8).

\section{Discussion}

Our hypothesis, verified here, was that medical and oral alteration was not the only factor responsible for harming children's OHRQol.
For example, the bivariate analysis showed that being a girl was significantly associated with a lower OHRQol $(p=0.03)$. This result corroborated several studies on the OHRQol of patients with clefts or facial alteration [17]. On the other hand, several studies with smaller cohorts did not show this difference $[18,19]$.

The physical and social deterioration of these diseases affecting the orofacial sphere may be more difficult for young and teenage girls who may be under significant social and aesthetic pressure.

Having a syndromic disease was the second reason for poor OHRQol $(p=0.01)$.

The syndromic forms, more serious and disabling because they were sometimes associated with other motor and / or intellectual handicaps, required more intensive overall care [20].

The study has shown in the multivariate model that having an isolated dental disease (without the presence of a facial cleft) was associated with a poorer OHRQol $(p=0.002)$ than those who suffered additionally from a facial cleft. Dental rare diseases can concern anomalies of: number of 
Table 3 CHILD-OIDP score by clinical and dental characteristics $(N=110)$

\begin{tabular}{|c|c|c|c|c|c|c|}
\hline \multirow[t]{2}{*}{ Clinical and dental characteristics } & \multirow[t]{2}{*}{$\mathrm{n}$} & \multirow[t]{2}{*}{$\%$} & \multicolumn{2}{|l|}{ CHILD-OIDP score } & \multirow[t]{2}{*}{ Beta $[95 \% \mathrm{Cl}]$} & \multirow[t]{2}{*}{$P$ value } \\
\hline & & & Median (Q1; Q3) & Min; max & & \\
\hline \multicolumn{7}{|l|}{ Syndromic disease } \\
\hline Yes & 32 & 32.3 & $33.0(16.3 ; 44.6)$ & $6.7 ; 77.5$ & $15.0[3.7 ; 26.3]$ & 0.01 \\
\hline No & 67 & 67.7 & $16.7(9.2 ; 30.0)$ & $6.7 ; 80.0$ & 0.0 & \\
\hline \multicolumn{7}{|l|}{ Type of disease } \\
\hline Disease with Oral cleft & 51 & 51.5 & $26.7(13.3 ; 39.2)$ & $6.7 ; 80.0$ & 0.0 & \\
\hline Dental disease & 48 & 48.5 & $16.3(9.2 ; 32.5)$ & $6.7 ; 77.5$ & $-10.0[-19.8 ;-0.2]$ & 0.05 \\
\hline \multicolumn{7}{|l|}{ Removable prosthesis } \\
\hline No & 101 & 91.8 & $20.8(10.0 ; 35.0)$ & $6.7 ; 80.0$ & 0.0 & . \\
\hline Yes & 9 & 8.2 & $30.0(13.3 ; 41.7)$ & $6.7 ; 44.2$ & $9.2[-14.3 ; 32.7]$ & 0.44 \\
\hline \multicolumn{7}{|l|}{ Fixed prosthesis } \\
\hline No & 100 & 90.9 & $21.7(10.4 ; 35.9)$ & $6.7 ; 80.0$ & 0.0 & . \\
\hline Yes & 10 & 9.1 & $14.6(7.5 ; 20.8)$ & $6.7 ; 66.7$ & $-5.9[-17.4 ; 5.6]$ & 0.31 \\
\hline \multicolumn{7}{|l|}{ Orthodontic treatment } \\
\hline No & 64 & 58.2 & $16.7(8.8 ; 33.4)$ & $6.7 ; 77.5$ & 0.0 & \\
\hline Yes & 46 & 41.8 & $24.2(10.8 ; 43.3)$ & $6.7 ; 80.0$ & $7.5[-2.5 ; 17.5]$ & 0.14 \\
\hline \multicolumn{7}{|l|}{ Painful teeth } \\
\hline No & 75 & 70.1 & $20.0(9.2 ; 34.2)$ & $6.7 ; 77.5$ & 0.0 & . \\
\hline Yes & 32 & 29.9 & $24.2(12.5 ; 44.6)$ & $6.7 ; 80.0$ & $4.2[-9.1 ; 17.5]$ & 0.53 \\
\hline \multicolumn{7}{|l|}{ Sensitive teeth } \\
\hline No & 58 & 56.3 & $20.4(9.2 ; 34.2)$ & $6.7 ; 77.5$ & 0.0 & \\
\hline Yes & 45 & 43.7 & $20.8(13.3 ; 39.2)$ & $6.7 ; 80.0$ & $0.0[-9.4 ; 9.4]$ & $>.99$ \\
\hline \multicolumn{7}{|l|}{ Decays } \\
\hline No & 83 & 76.9 & $21.7(10.0 ; 35.0)$ & $6.7 ; 77.5$ & 0.0 & . \\
\hline Yes & 25 & 23.1 & $20.8(9.2 ; 41.7)$ & $6.7 ; 80.0$ & $-0.9[-13.0 ; 11.2]$ & 0.88 \\
\hline \multicolumn{7}{|c|}{ Space between deciduous teeth did not fill } \\
\hline No & 40 & 38.1 & $21.7(9.2 ; 37.5)$ & $6.7 ; 77.5$ & 0.0 & \\
\hline Yes & 65 & 61.9 & $19.2(10.8 ; 31.7)$ & $6.7 ; 80.0$ & $-2.5[-13.3 ; 8.3]$ & 0.65 \\
\hline \multicolumn{7}{|l|}{ Deciduous teeth falling } \\
\hline No & 44 & 40.4 & $17.1(7.9 ; 32.5)$ & $6.7 ; 62.5$ & 0.0 & . \\
\hline Yes & 65 & 59.6 & $24.2(11.7 ; 39.2)$ & $6.7 ; 80.0$ & $6.7[-2.4 ; 15.8]$ & 0.15 \\
\hline \multicolumn{7}{|l|}{ Colored teeth } \\
\hline No & 64 & 61.0 & $21.3(10.0 ; 37.5)$ & $6.7 ; 72.5$ & 0.0 & . \\
\hline Yes & 41 & 39.0 & $21.7(10.0 ; 30.8)$ & $6.7 ; 77.5$ & $0.0[-9.9 ; 9.9]$ & $>.99$ \\
\hline \multicolumn{7}{|l|}{ Anomaly of size and shape of teeth } \\
\hline No & 33 & 32.7 & $14.2(7.5 ; 24.2)$ & $6.7 ; 51.7$ & $10.0[1.0 ; 19.0]$ & \\
\hline Yes & 68 & 67.3 & $24.6(12.5 ; 42.5)$ & $6.7 ; 80.0$ & 0.0 & 0.03 \\
\hline \multicolumn{7}{|l|}{ Teeth alignment problems } \\
\hline No & 21 & 19.3 & $15.8(9.2 ; 35.0)$ & $6.7 ; 66.7$ & 0.0 & . \\
\hline Yes & 88 & 80.7 & $21.7(10.8 ; 36.7)$ & $6.7 ; 80.0$ & $5.9[-8.1 ; 19.9]$ & 0.41 \\
\hline \multicolumn{7}{|l|}{ Gum bleeding } \\
\hline No & 81 & 74.3 & $18.3(9.2 ; 31.7)$ & $6.7 ; 72.5$ & 0.0 & \\
\hline Yes & 28 & 25.7 & $26.7(13.0 ; 43.4)$ & $6.7 ; 80.0$ & $5.9[-6.6 ; 18.4]$ & 0.35 \\
\hline
\end{tabular}

Swollen gums 
Table 3 CHILD-OIDP score by clinical and dental characteristics $(N=110)$ (Continued)

\begin{tabular}{|c|c|c|c|c|c|c|}
\hline \multirow[t]{2}{*}{ Clinical and dental characteristics } & \multirow[t]{2}{*}{$\mathrm{n}$} & \multirow[t]{2}{*}{$\%$} & \multicolumn{2}{|l|}{ CHILD-OIDP score } & \multirow[t]{2}{*}{ Beta $[95 \% \mathrm{Cl}]$} & \multirow[t]{2}{*}{$P$ value } \\
\hline & & & Median (Q1; Q3) & Min; $\max$ & & \\
\hline No & 89 & 85.6 & $17.5(9.2 ; 34.2)$ & $6.7 ; 77.5$ & 0.0 & \\
\hline Yes & 15 & 14.4 & $25.0(13.3 ; 44.2)$ & $6.7 ; 80.0$ & $7.5[-6.2 ; 21.2]$ & 0.28 \\
\hline \multicolumn{7}{|l|}{ Mouth ulcers, aphta } \\
\hline No & 81 & 75.0 & $18.3(9.2 ; 33.3)$ & $6.7 ; 77.5$ & 0.0 & \\
\hline Yes & 27 & 25.0 & $24.2(13.3 ; 45.0)$ & $6.7 ; 80.0$ & $5.9[-8.7 ; 20.5]$ & 0.42 \\
\hline \multicolumn{7}{|l|}{ Bad breath } \\
\hline No & 76 & 70.4 & $21.7(9.2 ; 37.5)$ & $6.7 ; 80.0$ & 0.0 & \\
\hline Yes & 32 & 29.6 & $20.4(12.1 ; 34.6)$ & $6.7 ; 77.5$ & $-0.9[-10.6 ; 8.8]$ & 0.85 \\
\hline \multicolumn{7}{|l|}{ Mouth deformation (cleft) } \\
\hline No & 68 & 63.6 & $17.9(8.8 ; 33.0)$ & $6.7 ; 77.5$ & 0.0 & \\
\hline Yes & 39 & 36.4 & $24.2(11.7 ; 43.3)$ & $6.7 ; 80.0$ & $5.9[-4.5 ; 16.3]$ & 0.26 \\
\hline \multicolumn{7}{|c|}{ Anomaly of eruption of definitive teeth } \\
\hline No & 43 & 40.6 & $20.0(8.3 ; 44.2)$ & $6.7 ; 66.7$ & 0.0 & \\
\hline Yes & 63 & 59.4 & $21.7(10.8 ; 30.0)$ & $6.7 ; 80.0$ & $1.7[-11.7 ; 15.1]$ & 0.80 \\
\hline \multicolumn{7}{|l|}{ Lack of definitive teeth } \\
\hline No & 51 & 50.5 & $20.8(10.0 ; 33.3)$ & $6.7 ; 77.5$ & 0.0 & \\
\hline Yes & 50 & 49.5 & $19.2(9.2 ; 40.0)$ & $6.7 ; 80.0$ & $-0.8[-11.0 ; 9.4]$ & 0.88 \\
\hline
\end{tabular}

Bold indicates $p$ values under 0.05 .

teeth (agenesis, anodontia, oligodontia, supernumerary teeth), size and shape of the teeth (microdontia, conical teeth...), structure of the teeth (amelogenesis imperfecta, enamel hypoplasia, hypomineralization, dentinogenesis imperfecta, dentinal dysplasia gingival and parodontal diseases (gingival overgrows, gingival fibromatosis, periodontitis), eruption, of the teeth (retainend teethn delay of eruption of the teeth ...). These diseases have functional repercussions but also aesthetic and social because the appearance can be largely altered. [6, 21-23]. However, this result appeared surprising since having a facial cleft seemed to be more disabling, especially if it is syndromic. Nevertheless, the diagnosis of facial clefts was prenatal. Our study led us to form the hypothesis that short and long-term treatments were well established and organized around a multidisciplinary team including psychological care. On the contrary, this study showed that difficulties related to funding and care pathways appear more present in patients with dental diseases (shape and color alteration of teeth, orthodontics treatment) (Table 3). The qualitative analysis also revealed that patients and their parents reported daily life-dental issues: pain, difficulty when eating, brushing teeth, altered

Table 4 CHILD-OIDP score by psychosocial characteristics ( $N=110)$

\begin{tabular}{|c|c|c|c|c|c|c|}
\hline \multirow[t]{2}{*}{ Psychosocial characteristics } & \multirow[t]{2}{*}{$\mathrm{n}$} & \multirow[t]{2}{*}{$\%$} & \multicolumn{2}{|l|}{ CHILD-OIDP score } & \multirow[t]{2}{*}{ Beta $[95 \% \mathrm{Cl}]$} & \multirow[t]{2}{*}{$P$ value } \\
\hline & & & Median (Q1; Q3) & Min; $\max$ & & \\
\hline \multicolumn{7}{|c|}{ Feeling of being sidelined in life } \\
\hline No & 72 & 69.9 & $16.7(8.3 ; 28.8)$ & $6.7 ; 77.5$ & 0.0 & \\
\hline Yes & 31 & 30.1 & $36.7(16.7 ; 51.7)$ & $6.7 ; 80.0$ & $20.0[6.8 ; 33.2]$ & 0.003 \\
\hline \multicolumn{7}{|l|}{ Feeling different } \\
\hline No & 38 & 36.9 & $16.7(8.3 ; 25.0)$ & $6.7 ; 77.5$ & 0.0 & \\
\hline Yes & 65 & 63.1 & $27.5(13.3 ; 44.2)$ & $6.7 ; 80.0$ & $10.8[1.6 ; 20.0]$ & 0.02 \\
\hline \multicolumn{7}{|c|}{ Relationship between hospital and private medicine } \\
\hline Good & 67 & 60.9 & $20.0(9.2 ; 30.0)$ & $6.7 ; 77.5$ & 0.0 & \\
\hline Bad & 22 & 20.0 & $19.2(11.7 ; 45.0)$ & $6.7 ; 80.0$ & $1.7[-15.2 ; 18.6]$ & 0.84 \\
\hline Doesn't know & 21 & 19.1 & $28.3(9.2 ; 40.0)$ & $6.7 ; 61.7$ & $8.3[-5.2 ; 21.8]$ & 0.23 \\
\hline
\end{tabular}

Bold indicates $p$ values under 0.05 . 
Table 5 CHILD-OIDP score - multivariable model $(N=110)$

\begin{tabular}{|c|c|c|}
\hline Clinical and dental characteristics & Beta $[95 \% \mathrm{Cl}]$ & $P$ value \\
\hline \multicolumn{3}{|l|}{ Gender } \\
\hline Male & 0.0 & - \\
\hline Female & $4.2[-2.8 ; 11.1]$ & 0.23 \\
\hline \multicolumn{3}{|l|}{ Age } \\
\hline $6-12$ years old & 0.0 & - \\
\hline 13-17 years old & $-0.9[-8.9 ; 7.1]$ & 0.82 \\
\hline \multicolumn{3}{|l|}{ Syndromic disease } \\
\hline Yes & $8.4[0.4 ; 16.3]$ & 0.04 \\
\hline No & 0.0 & \\
\hline \multicolumn{3}{|l|}{ Type of disease } \\
\hline Disease with facial cleft & 0.0 & . \\
\hline Dental disease & $-10.8[-17.6 ;-4.0]$ & 0.002 \\
\hline \multicolumn{3}{|l|}{ Problem of size and shape of teeth } \\
\hline Yes & $9.2[2.9 ; 15.4]$ & 0.005 \\
\hline No & 0.0 & \\
\hline \multicolumn{3}{|l|}{ Feeling of being sidelined in life } \\
\hline Yes & $20.0[6.9 ; 33.1]$ & 0.003 \\
\hline No & 0.0 & . \\
\hline
\end{tabular}

Bold indicates $p$ values under 0.05 .

tooth color, reduced chewing surface, lack of saliva, and restricted mouth opening. These issues did not appear in the quantitative analysis.

The third issue associated with a lower OHRQol was the renouncement of dental care $(p=0.01)$. This renouncement may be explained by many reasons such as financial cost, easy access to care, and difficulty to choose an expert practitioner to perform the complex treatments required. Oral care for children suffering from rare dental diseases (oligodontia, ectodermal dysplasia, for example) most often required multidisciplinary treatments include orthodontics and sometimes orthognathic surgery, conservative care, removable prosthesis at first and conventional fixed dental prosthesis and implant prosthetic rehabilitation at the end of growth [24-26]. The treatments are long and are not or only partly covered by health insurance. Moreover, treatments become more complex and expensive with age. Therefore, there is in increasing correspondence between the renouncement of care and worsening OHRQol (Table 2). Qualitative analysis revealed that cost was an issue that worried parents. In France, the socialized share of expenses incurred by the prosthetic and orthodontic rehabilitation of children and adults with rare orofacial diseases is not greater than for healthy patients, except for implants (without prosthesis) in the case of ectodermal dysplasia. No care scheme is currently planned for patients suffering from diseases affecting the oral sphere and whose lifelong care will be long and expensive. For all these reasons, we propose that a "rare orofacial disease care package" would be a good health policy for improving the OHRQol of patients with dental diseases.

The qualitative analysis also showed that the renouncement of dental care increases with the rarity of the disease. Parents and patients mentioned difficulties regarding diagnosis and surgery [27].

Feeling isolated, alone and different from other children was significantly associated with a lower OHRQol

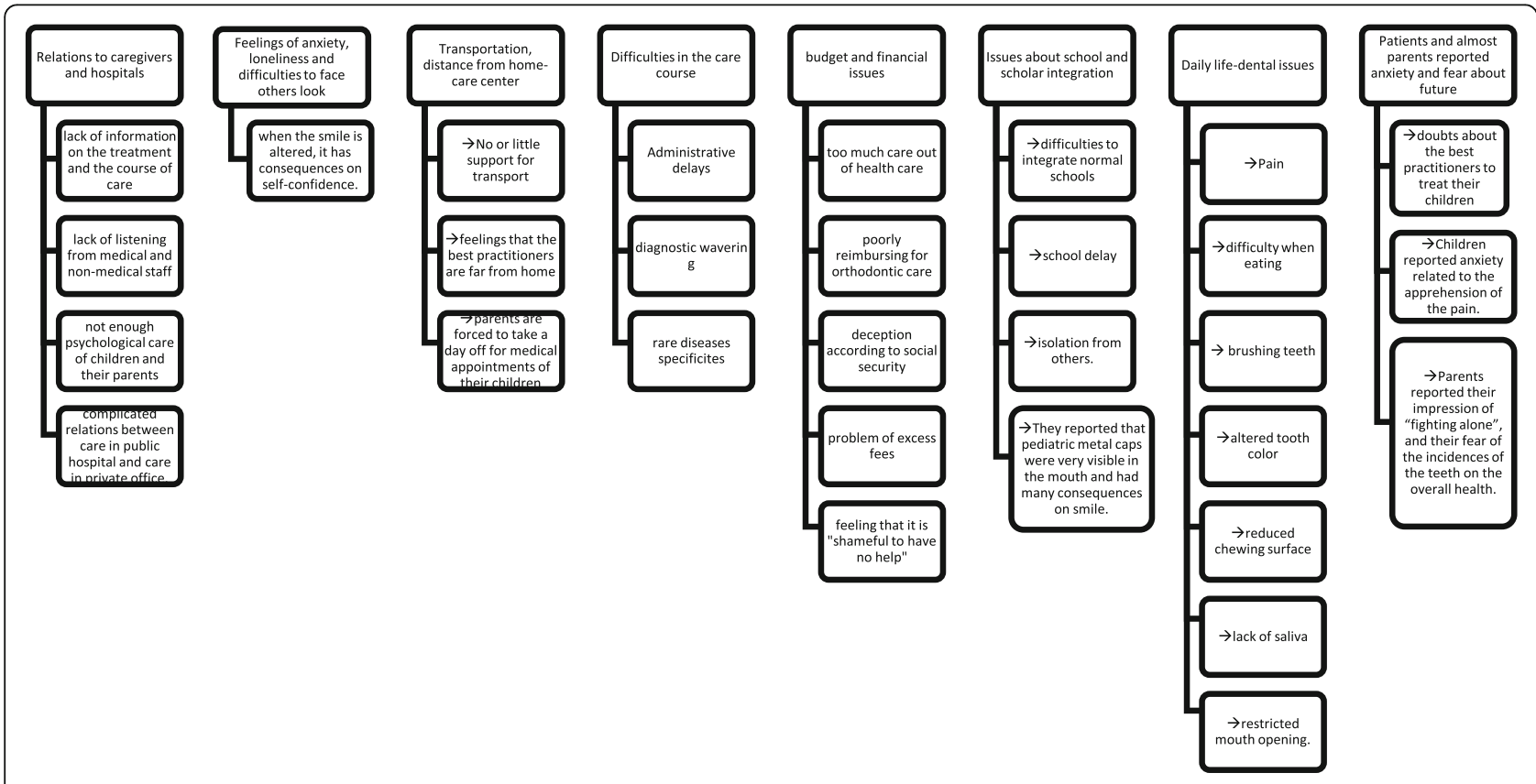

Fig. 2 Categories and sub-categories of qualitative analysis topics 
in the quantitative analysis. In the qualitative analysis, parents reported that their children were anxious about their future and their daily lives. Their appearance was sometimes greatly altered, and the gaze of others is a source of discomfort and anxiety. Lack of self-confidence, fear of smiling and the feeling of being beautiful appeared to be important for these young people. It is important to systematically make available help and psychological support during childhood and during the transition from pediatric to adult medical treatment. The literature showed that appearance and speech were the most frequently discussed points for children with facial clefts. Individuals with facial clefts may struggle with the psychological and social sequels of having differences in their appearance and speech [28].

This lack of psychological care has been accompanied, according to the qualitative analysis of the verbatim comments, by poor communication on the part of doctors. Children and their families reported anxiety about the future and the lack of responses to their questions about future treatments. This study has shown the interest of the identification of psychological factors that could be used to improve children's self-esteem and OHRQol.

Very few studies have mixed quantitative and qualitative analyzes regarding rare orofacial diseases [29, 30]. The existing literature with lip and/or palate cleft has focused almost exclusively on the medical aspects of care rather than patient experience, on objective measures rather than subjective self-perceptions, and on deficits rather than strengths.

The literature showed that the OHRQol of children with oral disease was much worse than in the general population [12, 31, 32]. The median CHILD-OIDP score was $20.08 / 100$ while for the general population it is between 2 and $8[11,33]$. The Child-OIDP score had the advantage of combining varied performances ranging from daily life to social relations. It had been shown in the literature that neither self-administration nor accompaniment by an investigator affect the results of questionnaires [34]. Thus, the fact that children responded with their parents, when they were not able to do it alone, did not limit the correct interpretation of the answers [35, 36].

\section{Limits}

In terms of bias, it is questionable whether those who responded to the study feel better or worse than those who did not respond. This can be seen in the qualitative analysis which may appear in some points as a list of grievances in which patients finally have a place to freely express their feelings and their distress about the management of the disease and the course of care. We did not analyze who did not answer, which could be a source of selection bias. However, the results corroborated those in the literature and, thanks to the qualitative analysis, provided much information on the feelings of patients, little studied so far.

Another point which may be discussed concerns the sample size and therefore the external validity of the findings and their representativeness. This study brings one of the largest samples on these topics studied in France to date. These data are the first on the management of these patients in a country where many political efforts have been made on rare diseases. This sample is interesting in relation to the initial population, strictly drawn and randomized, because it keeps the initial stratification (on gender, sex, type of disease) and the findings verify our initial hypothesis.

Our objective was not to conduct a study measuring statistical inference or to bring prognostic factors. The aim of this study was to better understand management of patients and how it could be improved. The results show inequalities in access to care with a lack of psychological support and financial coverage for their care. This data will be interesting to compare with other countries in the future.

With regard to the large number of diseases studied, they have in common the oral and social handicaps in their different syndromic composition's. These disabilities produce significant social inequalities. The stratification on age, sex and type of disease in the sample are clearly shown in the results by showing sub-groups of patients less well managed on both the medical and psychological sides.

With the contribution of the analytical results from the qualitative study, this study will be an important basis for other intervention studies.

\section{Strengths}

Although we did not carry out real mixed-method research, our study was greatly enriched by the analysis of the patients' and parents' verbatim comments.

The qualitative analysis highlighted topics that have not been explored through quantitative analysis, such as the fear of the future, shared by children and parents, the perception of feeling alone with the disease, from the standpoint of the care path and the overall integration of the child. This qualitative analysis will provide new topics and variables for future quantitative studies.

The lives of these children are clearly affected by their illnesses, but as the results of the quantitative analysis, and more precisely those of the qualitative analysis, have shown, the purely dental and oral parameters did not stand out as being clearly significantly related to the OHRQol as expressed in the study.

These conclusions are interesting because, so far, very few studies have shown the possible associations between psychosocial and socioeconomic factors related to 
the OHRQoL affected by these pathologies. Oral and dental explanations are often given without taking into consideration the whole existence of the child and their parents. What does it mean to be a carrier of a RD that affects appearance, whose necessary care is very expensive and poorly reimbursed whose care course, is chaotic?

In this study, all the results converged towards a need to improve the legibility of care pathways and financial coverage of treatments. Public policies must improve existing procedures so that no child with a rare disabling illness at the level of function and social acceptance is obliged to give up the care that is essential to their wellbeing and OHRQoL This study managed to provide several answers to these questions and suggest orientations in terms of health policy.

\section{Conclusion}

Although many efforts have been made in recent years regarding policies designed to improve access to the diagnosis and care of patients with RD in France, care pathways remain very complex for patients and their families. Financial support for necessary and oral care is still a big problem for families who must give up certain of its essential aspects.

Public policies must improve procedures so that no child with a rare disabling illness at the level of function and social acceptance has to give up the care essential to their well-being and OHRQoL. This study managed to provide some answers to these questions and to suggest orientations in terms of health policy. In addition to working for a better financial support of the treatments, a psychological care adapted to the specificities of each patient should be implemented. This study should be completed and enriched by other research to bring real recommendations in terms of public health for these young patients in their care course. Concerning the impact and the financial burden of these diseases, it would be interesting to conduct medico-economic evaluation studies and to evaluate the costs generated in a macro and micro-economic dimension of these diseases. In addition, it would be interesting to imagine interventional studies to create levers to improve children's psychosocial skills and to measure what could be done to improve the psychological care of patients and their caregivers.

\section{Additional file}

Additional file 1: Full Patients' Verbatim Comments. (DOCX 19 kb)

\section{Abbreviations}

ALD: Long Term Disease; CMUc: Universal social coverage; OHRQoL: Oral health-related quality of life; RD: Rare disease

\section{Acknowledgements}

The authors wish to thank the members of the Head, Neck and Teeth French Rare Diseases Network: all the medical and non-medical staff in competence and reference centres.

The authors wish also to thank the members of the URC research lab in Robert Debré Hospital, Paris: Béatrice Andriss, Adyla Yacoubi, Thérèse Kolta, Pierre Coste.

\section{Authors' contributions}

All the authors were involved in the design of the study. LF, BAL, MCM, AP, $\mathrm{OA}, \mathrm{MDM}$ treated the study patients and aided data collection. LF collected the data. LF and PB analyzed the data. LF, MDM and CA drafted the first and further versions of the manuscript. All the authors reviewed and revised the manuscript and approved its final version. Overall responsibility: LF.

\section{Funding}

One funding/research grant was received to support this study from University Paris-Diderot (Action structurante Dental faculty Garancière). Strasbourg Patients' enrollment was possible through the EU-funded project (ERDF) A27 "Oro-dental manifestations of rare diseases", supported by the RMT-TMO Offensive Sciences initiative, INTERREG IV Upper Rhine program, and the INTERREG V RARENET program.

\section{Availability of data and materials}

The datasets during and/or analyzed during the current study are available from the corresponding author on reasonable request.

\section{Ethics approval and consent to participate}

Ethical approvals for this study were obtained from the advisory committee on data processing in health research (Comité Consultatif sur le Traitement de I'Information en matière de Recherche dans le domaine de la santé (CCTIRS), the national committee of data processing and civil liberties (Commission Nationale de l'Informatique et des libertés (CNIL)), and the ethical research committee (Comité de Protection des Personnes (CPP) in Robert Debré Hospital, Paris).

Strasbourg Patients were identified using the D [4]/phenodent registry, a Diagnosing Dental Defects Database, approved by CNIL (French National Commission for Informatics and Liberty, number 908416). It was acknowledged by the CPP (person protection committee) Est IV December 11 th 2012

\section{Consent for publication}

All the patients or their parents gave written informed consent for participation in the study and the publication of the study results.

\section{Competing interests}

The authors declare that they have no competing interests.

\section{Author details}

${ }^{1}$ Sorbonne Paris Cité, INSERM, Laboratoire ECEVE UMR1123, Université Paris Diderot, Paris, France. ${ }^{2}$ Centre de Reference, Maladies Orales et Dentaires Rares, Hopital Rothschild, APHP, Paris, France. ${ }^{3}$ Filière de Santé Maladies Rares TETECOU, Malformations Rares de la tête, du cou et des dents, Hôpital Necker, Paris, France. ${ }^{4}$ Sorbonne Paris Cité, INSERM, Laboratoire de Physiopathologie Orale et Moléculaire, Université Paris Diderot, UMRS, 1138 Paris, France. ${ }^{5} \mathrm{AP}-\mathrm{HP}$, Unité d'Epidémiologie Clinique, Hôpital Robert Debré, Paris, France. ${ }^{6}$ Sorbonne Paris-Cité, INSERM U1123 et CIC-EC 1426, Université Paris Diderot, Paris, France. ${ }^{7}$ Centre de Competence, Maladies orales et Dentaires Rares, CHU de Nantes, Nantes, France. ${ }^{8}$ Centre de Référence, Maladies orales et dentaires rares, Pôle de Médecine et Chirurgie Bucco-dentaires, Hôpitaux Universitaires de Strasbourg, Strasbourg, France. ${ }^{9}$ Centre de Référence des Fentes et Malformations Faciales, Hôpital Necker, AP-HP, Paris, France. ${ }^{10}$ Université Paris Descartes-Sorbonne Paris Cité, Paris, France. ${ }^{11}$ Centre de Compétence des Fentes et Malformations Faciales, $\mathrm{CHU}$ de Rennes, Rennes, France. ${ }^{12}$ INSERM UMRS1163 Bases Moléculaires et Physiopathologiques des Ostéochondrodysplasies, Institut Imagine, Necker, Paris, France. 


\section{Received: 21 August 2018 Accepted: 27 May 2019} Published online: 04 June 2019

\section{References}

1. Broder $\mathrm{HL}$, Wilson-Genderson M, Sischo L, Norman RG. Examining factors associated with oral health-related quality of life for youth with cleft. Plast. Reconstr. Surg. 2014;133:828e-34e Available from: http://www. pubmedcentral.nih.gov/articlerender.fcgi?artid=4120869\&tool= pmcentrez\&rendertype=abstract [cited 2015 Nov 12].

2. Eslami N, Majidi MR, Aliakbarian M, Hasanzadeh N. Oral health-related quality of life in children with cleft lip and palate. J. Craniofac. Surg. 2013;24: e340-3 Available from: http://www.ncbi.nlm.nih.gov/pubmed/23851861 [cited 2015 Nov 12].

3. Geels LM, Kieffer JM, Hoogstraten J, Prahl-Andersen B. Oral health-related quality of life of children with craniofacial conditions. Cleft Palate. Craniofac. J. 2008;45:461-7 Available from: http://www.ncbi.nlm.nih.gov/pubmed/ 18788871 [cited 2015 Oct 30].

4. Locker D, JOKOVIC A, PRAKASH P, Tompson B. Oral health-related quality of life of children with oligodontia. Int J Paediatr Dent. 2010;20: 8-14 Available from: http://doi.wiley.com/10.1111/j.1365-263X.2009. 01001.x [cited 2016 Jul 13].

5. Gatti GL, Freda N, Giacomina A, Montemagni M, Sisti A. Cleft Lip and Palate Repair. J. Craniofac. Surg. 2017;1. Available from: http://www.ncbi.nlm.nih. gov/pubmed/28906329 [cited 2017 Oct 11]

6. Saltnes SS, Jensen $J$, Sæves R, Nordgarden H, Geirdal A $\varnothing$. Associations between ectodermal dysplasia, psychological distress and quality of life in a group of adults with oligodontia. Acta Odontol. Scand. 2017;75:1-9 Available from: http://www.ncbi.nlm.nih.gov/ pubmed/28754083 [cited 2017 Aug 26]

7. Geirdal AØ, Saltnes SS, Storhaug K, Åsten P, Nordgarden H, Jensen JL. Living with orofacial conditions: psychological distress and quality of life in adults affected with Treacher Collins syndrome, cherubism, or oligodontia/ ectodermal dysplasia-a comparative study. Qual. Life Res. 2015;24:927-35 Available from: http://www.pubmedcentral.nih.gov/articlerender.fcgi?artid= 4366539\&tool=pmcentrez\&rendertype=abstract [cited 2015 Jul 16].

8. Glener AD, Allori AC, Shammas RL, Carlson AR, Pien IJ, Aylsworth AS, et al. A population-based exploration of the social implications associated with cleft Lip and/or Palate. Plast Reconstr Surg - Glob Open. 2017;5:e1373 Available from: http://www.ncbi.nlm.nih.gov/pubmed/28740782 [cited 2017 Oct 20].

9. Massenburg BB, Jenny HE, Saluja S, Meara JG, Shrime MG, Alonso N. Barriers to Cleft Lip and Palate Repair Around the World. J. Craniofac. Surg. 2016;27: 1741-5 Available from: http://www.ncbi.nlm.nih.gov/pubmed/27763973 [cited 2017 Oct 20].

10. Locker D, Gibson B. The concept of positive health: a review and commentary on its application in oral health research. Community Dent Oral Epidemiol. 2006;34:161-73 Available from: http://www.ncbi.nlm.nih. gov/pubmed/16674748 [cited 2017 Oct 11].

11. Tubert-Jeannin S, Pegon-Machat E, Gremeau-Richard C, Lecuyer M-M, Tsakos G. Validation of a French version of the Child-OIDP index. Eur. J. Oral Sci. 2005;113:355-62 Available from: http://www.ncbi.nlm.nih.gov/pubmed/ 16202021 [cited 2016 Jan 2].

12. Gherunpong S, Tsakos G, Sheiham A. Developing and evaluating an oral health-related quality of life index for children; the CHILD-OIDP. Community Dent. Health. 2004;21:161-9 Available from: http://www.ncbi.nlm.nih.gov/ pubmed/15228206 [cited 2017 Apr 21].

13. Heaney A, Wilburn J, Langmead S, Blakeley J, Huson S, Jim C, et al. A qualitative study of the impact of plexiform neurofibromas on need fulfilment in adults with neurofibromatosis type 1. SAGE Open Med. 2019;7: 205031211982968. Available from: http://www.ncbi.n/m.nih.gov/pubmed/ 30800298 [cited 2019 Mar 11]

14. O'cathain A, Murphy E, Nicholl J. The Quality of Mixed Methods Studies in Health Services Research. J. Health Serv. Res. Policy. 2008;13:92-8 Available from: http://www.ncbi.nlm.nih.gov/pubmed/18416914 [cited 2019 Mar 11]

15. O'Cathain A, Murphy E, Nicholl J. Why, and how, mixed methods research is undertaken in health services research in England: a mixed methods study. BMC Health Serv Res. 2007;7:85 Available from: https://bmchealthservres biomedcentral.com/articles/10.1186/1472-6963-7-85 [cited 2019 Feb 17].

16. Shrestha P. Introduction to research methods in psychology 3rd ed. D. Howitt D. Cramer Pearson. Available from: http://www.academia.edu/ 34674134/Introduction_to_research_Methods_in_Psychology_3rd_ed._D. Howitt_D._Cramer_Pearson [cited 2018 Aug 17]
17. Klassen AF, Riff KWW, Longmire NM, Albert A, Allen GC, Aydin MA, et al. Psychometric findings and normative values for the CLEFT-Q based on 2434 children and young adult patients with cleft lip and/or palate from 12 countries. Can. Med. Assoc. J. 2018;190:E455-62 Available from: http://www. ncbi.n/m.nih.gov/pubmed/29661814 [cited 2018 Jun 30].

18. Sundell AL, Törnhage C-J, Marcusson A. A comparison of health-related quality of life in 5- and 10-year-old Swedish children with and without cleft lip and/or palate. Int J Paediatr Dent. 2017;27:238-46 Available from: http:// doi.wiley.com/10.1111/ipd.12253 [cited 2018 Jun 30].

19. Bos A, Prahl C. Oral health-related quality of life in Dutch children with cleft lip and/or palate. Angle Orthod. 2011;81:865-71 Available from: http://www. ncbi.nlm.nih.gov/pubmed/21506658 [cited 2016 Jul 11].

20. Vuletic M, Marcinko D, Vrazic D, Milosevic M, Dediol E, Knezevic $P$ Development of a valid and reliable instrument for the assessment of quality of life in adolescents with clefts - detection of potential mental health issues. Psychiatr Danub. 2017;29:360-8 Available from: http://www. ncbi.nlm.nih.gov/pubmed/28949317 [cited 2018 Jan 24].

21. Maroulakos G, Artopoulou II, Angelopoulou MV, Emmanouil D. Removable partial dentures vs overdentures in children with ectodermal dysplasia: two case reports. Eur Arch Paediatr Dent. 2016;17:205-10 Available from: http:// www.ncbi.nlm.nih.gov/pubmed/26645986 [cited 2019 Mar 11].

22. Hsieh Y-L, Razzoog M, Garcia Hammaker S. Oral Care Program for Successful Long-Term Full Mouth Habilitation of Patients with Hypohidrotic Ectodermal Dysplasia. Case Rep. Dent. 2018;2018:1-7 Available from: http:// www.ncbi.nlm.nih.gov/pubmed/30627453 [cited 2019 Mar 11].

23. Saltnes SS, Geirdal AØ, Saeves R, Jensen $J$, Nordgarden $H$. Experiences of daily life and oral rehabilitation in oligodontia - a qualitative study. Acta Odontol. Scand. 2019;77:197-204 Available from: http://www.ncbi.nlm.nih. gov/pubmed/30646789 [cited 2019 Mar 11].

24. Paulus C, Martin P. Hypodontia due to ectodermal dysplasia: rehabilitation with very early dental implants. Rev Stomatol Chir Maxillofac Chir Orale. 2013;114:e5-8 Available from: http://www.ncbi.nlm.nih.gov/pubmed/ 23838251 [cited 2015 Jul 16].

25. Durstberger G, Celar A, Watzek G. Implant-surgical and prosthetic rehabilitation of patients with multiple dental aplasia: a clinical report. Int J Oral Maxillofac Implants. 14:417-23 Available from: http://www.ncbi.nlm.nih. gov/pubmed/10379116 [cited 2016 Dec 31].

26. Wojtyńska E, Bączkowski B, Przybyłowska D, Cierech M, Mierzwińska-Nastalska E, Zadurska M. A multidisciplinary treatment of patients with craniofacial disorders. Own experience. Dev. Period Med. 19:464-70 Available from: http://www.ncbi. nlm.nih.gov/pubmed/26982754 [cited 2016 Dec 31].

27. Toupenay S, Razanamihaja N, Berdal A, Boy-Lefèvre ML. Rare diseases with oral components: care course and quality of life. Community Dent. Health. 2013;30: 10-4 Available from: http://www.ncbi.nlm.nih.gov/pubmed/23550500 [cited 2017 Jan 2].

28. Wong Riff KWY, Tsangaris E, Goodacre TEE, Forrest CR, Lawson J, Pusic AL, et al. What Matters to Patients With Cleft Lip and/or Palate. Cleft Palate-Craniofacial J. 2018;55:442-50 Available from: http://www.ncbi.nlm.nih.gov/pubmed/29437508 [cited 2018 Feb 21]

29. Awoyale T, Onajole AT, Ogunnowo BE, Adeyemo WL, Wanyonyi KL, Butali A. Quality of life of family caregivers of children with orofacial clefts in Nigeria: a mixed-method study. Oral Dis.; 2016 ;22:116-122. Available from: http:// www.ncbi.nlm.nih.gov/pubmed/26456150 [cited 2018 May 27]

30. Stock NM, Feragen KB, Rumsey N. "It Doesn't All Just Stop at 18": Psychological Adjustment and Support Needs of Adults Born With Cleft Lip and/or Palate. Cleft Palate-Craniofacial J. 2015:52:543-54 Available from: http://www.cpcjournal.org/doi/10.1597/14-178 [cited 2018 Jun 13].

31. Castro R de AL, Portela MC, Leão AT, de Vasconcellos MTL. Oral healthrelated quality of life of 11- and 12-year-old public school children in Rio de Janeiro. Community Dent. Oral Epidemiol. 2011;39:336-44. Available from: http://doi.wiley.com/10.1111/j.1600-0528.2010.00601.x [cited 2017 Apr 21]

32. Kumar S, Kumar A, Badiyani B, Kumar A, Basak D, Ismail MB. Oral health impact, dental caries experience, and associated factors in 12-15-year-old school children in India. Int. J. Adolesc. Med. Health. 2017;29 Available from: http://www.degruyter.com/view/j/ijamh.2017.29.issue-2/ijamh-2015-0041/ ijamh-2015-0041.xml [cited 2017 Apr 21].

33. Nurelhuda NM, Ahmed MF, Trovik TA, Åstrøm AN. Evaluation of oral health-related quality of life among Sudanese schoolchildren using child-OIDP inventory. Health Qual Life Outcomes. 2010;8:152 Available from: http://hqlo.biomedcentral.com/articles/10.1186/1477-7525-8-152 [cited 2017 Apr 21]. 
34. Tsakos G, Bernabé E, O'Brien K, Sheiham A, de Oliveira C. Comparison of the self-administered and interviewer-administered modes of the child-OIDP. Health Qual. Life Outcomes; 2008;6:40. Available from:/pmc/articles/ PMC2424040/?report=abstract. [cited 2016 Jan 2]

35. Mtaya M, Astrom AN, Brudvik P. Malocclusion, psycho-social impacts and treatment need: A cross-sectional study of Tanzanian primary school-

children. BMC Oral Health. 2008;8:14. Available from: http://www.ncbi.nlm. nih.gov/pubmed/18460198 [cited 2018 Mar 21]

36. Sischo L, Wilson-Genderson M, Broder HL. Quality-of-Life in Children with Orofacial Clefts and Caregiver Well-being. J. Dent. Res. 2017;96: 1474-1481. Available from: http://www.ncbi.nlm.nih.gov/pubmed/ 28813183 [cited 2018 Feb 21]

\section{Publisher's Note}

Springer Nature remains neutral with regard to jurisdictional claims in published maps and institutional affiliations.

Ready to submit your research? Choose BMC and benefit from:

- fast, convenient online submission

- thorough peer review by experienced researchers in your field

- rapid publication on acceptance

- support for research data, including large and complex data types

- gold Open Access which fosters wider collaboration and increased citations

- maximum visibility for your research: over $100 \mathrm{M}$ website views per year

At BMC, research is always in progress.

Learn more biomedcentral.com/submissions 